STRUCTURAL SCIENCE CRYSTAL ENGINEERING MATERIALS

ISSN 2052-5206

Keywords: book review; crystals

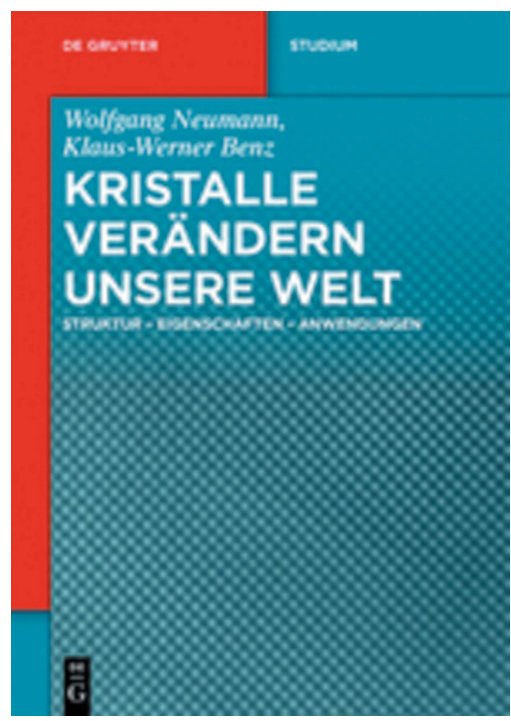

(C) 2019 International Union of Crystallography

\section{Kristalle verändern unsere Welt. Struktur - Eigenschaften - Anwendungen. By Wolfgang Neumann and Klaus-Werner Benz. De Gruyter, 2018, Paperback, Pp. xvi+282. Price EUR 39.95, USD 45.99, GBP 36.50. ISBN 978-3-11-043889-5}

\author{
Volker Kahlenberg* \\ Institute of Mineralogy and Petrography, University of Innsbruck, Austria. *Correspondence e-mail: \\ volker.kahlenberg@uibk.ac.at
}

The text by Neumann and Benz has been written as a 'user-friendly' introduction to the importance of crystals in modern technology and of crystallography as an interdisciplinary science providing input for a large number of different research areas. The work should be equally useful for undergraduate students in materials and Earth sciences, chemistry, physics and biology, as well as for the interested lay person and even high-school students.

The first chapter supplies the reader with a 'non-mathematical' but nevertheless comprehensive survey of the basic concepts of crystal geometry including morphological and structural symmetry aspects. Good-quality illustrations help in the understanding of the topics addressed. Special emphasis is laid on a detailed overview of the historical evolution of the definition of what a crystal actually is - including all the trials and tribulations. To my mind, it is especially this part of the book where people involved in teaching crystallography at university levels may find new and interesting background information for their own lectures. In Chapter 2, the authors deal with the special importance of silicon and other semiconductors and their various applications providing the basis for one of the most rapid industrial revolutions. Aspects of growing large crystals are included as well. Chapter 3 is devoted to nanocrystalline materials representing the other end of the crystalline dimensional scale so to say. Chaper 4 focuses on the interrelationships between crystallography and related fields on national and international levels. Within this context the roles of the International Union of Crystallography and the International Year of Crystallography 2014 are highlighted. Finally, the biographies of six prominent women in crystallography are presented. More detailed information to that presented in Chapter 1 is given in an Appendix, where additional tables and figures can be found.

All in all, the book satisfies the requirements for a popular introductory text. It is concise, well presented and full of excellent hints. However, its attractiveness for the international crystallographic community would be surely enhanced with an English translation. 